\title{
La prevención sanitaria en Mallorca (1718-1756)
}

\author{
José María Jesús Cortés Verdaguer *
}

\begin{abstract}
RESUMEN ABSTRACT
El presente artículo trata sobre la organización y ejecución de las medidas de prevención sanitaria en Mallorca durante la primera mitad del siglo XVIII, en función de las epidemias de peste aparecidas en diversos lugares del Mediterráneo. Este análisis

parte del nuevo marco normativo $e$ institucional inaugurado por la nueva dinastía borbónica en España en materia de prevención sanitaria a partir de 1718, sin olvidar las peculiaridades

que el hecho insular planteaba en el caso de Mallorca.

This article deals with the organization and execution measures of health prevention in Majorca during the $18^{\text {th }}$ century, in the presence of plagues that appear in several places of the Mediterranean Sea. This analysis starts with the new health regulations and the new institutions of Bourbon monarchy in Spain since 1718 , and it considers the circumstances derived from the fact that Majorca is an island.
\end{abstract}

\section{INTRODUCCIÓN}

El conocimiento de la realidad histórica propia del siglo xVIII en Mallorca ha avanzado mucho merced a los trabajos de investigación realizados en los últimos años, los cuales han superado un estricto marco político, profundizando en aspectos sociales y económicos diversos. Así, A. Bibiloni Amengual ha estudiado el comercio exterior de Mallorca entre 
1650 y $1720^{1}$, mientras $C$. Manera ha tratado las relaciones del comercio mallorquín con el capital mercantil entre 1720 y $1800^{2}$, sin olvidar los trabajos llevados a cabo por otros autores. Sin embargo, aun siendo mucho lo investigado todavía quedan parcelas pendientes de análisis cuyo estudio es necesario para completar y comprender la realidad histórica del siglo aludido.

Una de estas parcelas viene constituida por las disposiciones sanitarias adoptadas para prevenir el contagio de enfermedades infecciosas, es decir, de las epidemias de peste procedentes del exterior. En un artículo, publicado en 1988, G. López Nadal ya se planteaba un estado de la cuestión ${ }^{3}$, contando además con las aportaciones debidas a E. Martín Corrales en relación a Cataluña ${ }^{4}$. Por tanto el presente estudio, teniendo en cuenta el panorama citado, se ocupa de las medidas de prevención sanitarias, en tanto en cuanto se articulan como marco normativo idóneo para dar respuesta a las situaciones de crisis, teniendo en cuenta además sus modalidades de ejecución, los destinatarios, los encargados de supervisar su aplicación y, en fin, los efectos generados como consecuencia de las mismas, tomando en consideración el archipiélago balear durante la primera mitad del siglo XVIII.

La transformación sufrida en el Reino de Mallorca tras la victoria de Felipe $V$ supuso una pérdida de protagonismo político y administrativo, en beneficio de las nuevas instituciones implantadas por la nueva monarquía con criterios de centralización y control. Pero las necesidades sanitarias hicieron que, junto al Ayuntamiento de Palma, la nueva Audiencia y la figura del Capitán General como instituciones más representativas del nuevo periodo, subsistiese una Junta de Morberos, heredera de la existente en siglos anteriores, aunque sufriendo una serie de cambios, con funciones de vigilancia y control sobre las embarcaciones llegadas al puerto de Palma y con atribuciones que se extendían por todo el litoral insular. Esta prevención sanitaria no sólo implicará la supervisión de las distintas autoridades, sino una auténtica movilización de recursos a nivel de toda la isla, ya sean humanos o financieros, que se añadirán a las consecuencias derivadas de su incidencia en el tráfico mercantil. De

Bibiloni Amengual, A., El comerç exterior de Mallorca (1650-1720). Palma, 1995.

MANERA, C., Comerç i capital mercantil a Mallorca (1720-1800). Palma, 1988.

LóPEZ NADAL, G., «Estructuras e instituciones sanitarias en los puertos del Levante ibérico entre los siglos xVI y XVII (una visión de conjunto)", en I Porti come emprese economice. Firenze, 1988.

4 Martín Corrales, E., "Dos obstáculos en las relaciones comerciales entre Cataluña y los Paises musulmanes en el siglo xVIII: el corso y la peste", en Primer Congrés d'Història Moderna de Catalunya. Barcelona, 1984, pp. 611-617. 
este modo, el sistema de torres y atalayas esparcidas a lo largo del litoral mallorquín, con sus dotaciones correspondientes, asumirá no sólo tareas de alerta y vigilancia costera, sino también cometidos de vigilancia sanitaria.

La evolución de la sanidad en Mallorca no es independiente de la que opera en otras regiones, donde también aparecen los correspondientes mecanismos de control, manteniendo su vigencia en épocas de paz y de guerra; asi la misma actividad de los corsarios mallorquines, debidamente documentada, se verá mediatizada por tales medidas cuando regresen a puerto, ya sea en solitario o acompañados de alguna presa.

Simultáneamente dentro de esta visión de conjunto merece destacarse la misma literatura de la época, donde coexisten obras de tono científico y novelas, siendo ambas exponentes de una línea de pensamiento típica de la sociedad europea, horrorizada ante la peste y sus consecuencias. Dentro de las primeras destaca una obra, publicada en 1736, titulada "Systema phísico-médico-político de la Peste" " ${ }^{5}$ cuyo contenido es un compendio de prevención sanitaria, mientras que podemos incluir en el segundo grupo «El Diario del año de la peste» de Daniel Defoe ${ }^{6}$, fechado en 1722.

El autor del primer texto manifiesta como éste había surgido por iniciativa de la Real y Suprema Junta de Sanidad (creada en octubre de 1720 en relación a la aparición de la peste en Marsella), con fines claramente didácticos, es decir, ilustrando sobre las medidas de prevención sanitaria más adecuadas para evitar el contagio, teniendo en cuenta la situación terrestre o marítima de las plazas en presencia. Las medidas de precaución que afectan a los lugares marítimos se explican en el capítulo primero del libro Segundo a lo largo de nueve apartados, y consisten ,básicamente, en controlar la entrada y salida de las embarcaciones, dirigiendo el tráfico hacia un único puerto, prohibiendo el comercio con las plazas infectadas y el desembarco clandestino de mercancías (contrabando). La embarcaciones arribadas debían someterse a inspección por el personal correspondiente (escribano, médico y cirujano), los cuales, habiendo examinado la documentación y el estado de salud de los ocupantes de la nave, contemplarían la posibilidad de admitirlos a cuarentena; cumplida ésta sin novedad, sufrían nuevo examen médico, cuyo resultado satisfactorio les suponía obtener «libertad de entrada y de comercio".

5 Díaz Salgado, J., Systema phísco-médico-político de la Peste. Madrid, 1736.

6 DEFoE, D., Diario del año de la peste. Barcelona, 1996. 
Finalmente se manifiesta, al igual que lo hará Daniel Defoe ${ }^{7}$, un recelo general hacia los musulmanes, cuyos puertos del Norte de Africa son considerados poco menos que lugares de contagio, y de los que es preciso guardarse, tanto en el caso de pacíficas relaciones comerciales como cuando se apresan barcos procedentes de alli. A esta actitud de rechazo no es ajena, en el caso español, la tradicional hostilidad habida entre unos y otros, con continuos enfrentamientos, considerando, además, como España había vuelto a ocupar Orán en 1732.

Todo ello retrata el espíritu de la sociedad de la época y de sus gobernantes, atenazados entre su deseo de enriquecerse y el temor al contagio, constituyendo una auténtica radiografía de la cuenca mediterránea.

La rendición de Mallorca ante las tropas de Felipe $V$ en julio de 1715 supuso no sólo el reconocimiento indiscutible de la nueva dinastía, sino un nuevo capítulo en la historia de la isla. Mucho se ha hablado de la política centralista de Felipe $\mathrm{V}$, teniendo sus defensores y detractores, aunque una cosa es evidente: la transformación de las antiguas instituciones en los territorios integrantes de la Corona de Aragón, Mallorca incluida, que perdieron su autonomía política y administrativa para entrar en una fase de dependencia y control de las autoridades instaladas en Madrid, y de sus representantes oficiales designados para dichos territorios. Entre estos representantes de más alto rango destaca la figura del Capitán General, magistrado que disponía de jurisdicción civil y militar, ostentando el mando de las tropas estacionadas en el espacio sometido a su autoridad, y presidiendo la Real Audiencia. Los Capitanes Generales eran referencia obligada para toda actuación administrativa ejecutada en el ámbito de su jurisdicción, y esto también debe entenderse en el caso de la aplicación de las normas de prevención sanitaria vigentes, de tal modo que los llamados a ejecutarlas no descuidaban mantenerles informados en todo momento, recabando su aprobación.

Mediante el Decreto de Nueva Planta, dado por Felipe $V$ en fecha 28 de noviembre de 1715, se abolió el Gran i General Consell como asamblea representativa del Reino de Mallorca, y sus competencias se encomendaron a la nueva Audiencia, tal y como quedó configurada a partir de 1715. Ésta, como ya se ha dicho, estaba presidida por el Capitán General, al que seguia el regente como cabeza judicial de la Audiencia, integrada a su vez por oidores o miembros de la sala civil, alcaldes del crimen o miembros de

\footnotetext{
Señala Daniel DefoE, como «abusando de las ideas de predestinación que profesaban, ..., iban sin preocuparse a los lugares infectados y conversaban con personas coritagiadas", en Diario del año..., pp. 20-21.
} 
la sala criminal y un fiscal. La Audiencia de Mallorca dependía del Consejo de Castilla en relación a sus apelaciones. La autoridad militar y el colegio judicial, actuando al unísono, formaban el Real Acuerdo.

También se produjeron importantes cambios en la nueva administración municipal, cesando los oficios de jurados con su poder ejecutivo y el sistema de insaculación empleado para designar a los mismos, ocupando su lugar un Ayuntamiento integrado por 20 regidores (16 del estamento de caballeros y 4 del de ciudadanos), nombrados por el rey, mediando informe de la Real Audiencia ${ }^{8}$. En 1718 surge la figura del intendente con competencias en justicia, hacienda, administración general (incluyendo tareas de salud pública) y administración militar (avituallamiento de tropas). Pese a reconocerse los derechos de los acreedores del antiguo Reino de Mallorca (Universal consignación), la autonomía económica y financiera desapareció, siendo el nuevo Estado borbónico, a través de sus agentes, quien se encargaba de establecer las cargas fiscales y recaudarlas, controlando, además, los impuestos anteriores. Entre las cargas fiscales figuraba una talla general de 32.000 pesos anuales, sufragada de acuerdo con la riqueza de cada vecino, a la que debían añadirse las tallas impuestas para sufragar gastos extraordinarios e imprevistos, entre ellos los ocasionados por la aplicación de medidas de prevención sanitaria ante el riesgo de contagios procedentes del exterior. Por lo dicho, se advierte como las relaciones entre las instituciones locales y quienes detentaban la autoridad serán de subordinación más que de coordinación, disponiendo las primeras de una esfera de actuación limitada.

\section{DE LA JUNTA DE MORBEROS A LA DIPUTACIÓN DE SANIDAD}

Para un territorio insular como Mallorca, aquejado durante toda la Edad Media y la Edad Moderna de una carestía casi continua de alimentos y productos de primera necesidad, se hacía necesario recurrir al transporte marítimo para asegurarse su suministro y, a veces, simultáneamente con estos productos se introducía el contagio de la peste en la Isla. En consecuencia la prevención del contagio preocupó a las autoridades desde temprana época. Coinciden diversos autores en precisar que la constitución efectiva de la Junta de Morberos o Morbería data de 1475, por iniciativa

\footnotetext{
8 VIDAL, J., "Informe y descripción de las instituciones de gobierno y de administración de Justicia y de las diversas poblaciones de la Isla de Mallorca, al concluir la Guerra de Sucesión a la Corona de España, enviado a Felipe $V$ por D. Miguel Malonda", en Fontes Rerum Balearium, vol. III (1980), pp. 267-282.
} 
del Gran i General Consell, es decir, se trataba de la institución creada por este organismo en virtud de sus competencias en materia de salud pública, con la finalidad de impedir que se introdujese el contagio de enfermedades infecciosas en Mallorca. Para ello se controlaba la arribada de cualquier embarcación, fuese sospechosa o no, estableciéndose las medidas que se consideraban más adecuadas, entre ellas la cuarentena 0 aislamiento por un periodo de tiempo determinado. De este modo, la sanidad preventiva estaba controlada por los morberos «designados anualmente por el Grande y General Consejo en número de tres en representación de los estamentos militar, ciudadano y de mercaderes. Los guardas de mar eran los encargados de la ejecución y puesta en práctica de las normas

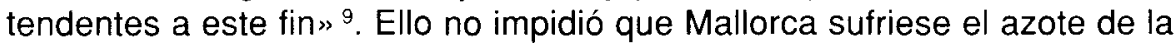
peste en 1504 y en 1523, aunque la epidemia que dejó peor recuerdo en la memoria colectiva fue la de 1652. Se introdujo en la isla desde Sóller, afectando a la capital y causando gran mortandad (tal vez unas 20.000 personas). Duró desde enero de 1652 hasta febrero de 1653 con unos periodos más virulentos que otros.

Ya en el siglo XVIII hemos visto como el Decreto de Nueva Planta de 1715 suprimió el Gran i General Consell y, en consecuencia, parece que también debía entenderse como suprimida la Junta de Morberos, dada su dependencia institucional del primero, pues los miembros de ésta eran designados por aquél anualmente mediante el sistema de insaculación. Sin embargo, incluso admitiendo tal supresión, no puede considerarse como definitiva. En efecto, ya constituido el Ayuntamiento de Palma, como institución de nuevo cuño, el 4 de agosto de 1718, Miguel Aleña, en representación del mismo, se dirigió al Capitán General, como máxima autoridad en Mallorca, señalando la necesidad de mantener la provisión de algunos oficios del antiguo Reino de Mallor$\mathrm{ca}$, siquiera fuese de modo interino, dados los intereses en juego, entre los que incluía al de Morberos. Su petición fue atendida y el Capitán General, que en aquella época era el Marqués de Casa-Fuerte, permitió que "continuasen en la misma forma y en los mismos sujetos que los servían por entonces, y hasta que S.M. ordenase otra cosa" ${ }^{10}$. De este modo, aparecen como Morberos: D. Antonio Dameto, D. Juan Amer de las Puntas y Martín Mayol, Capitán de Mar. La continuación del oficio de Morberos en las personas aludidas, debidamente documentada, queda fuera de toda duda, y pone de relieve cómo dicho oficio subsistió con posterioridad al Decreto de Nueva Planta y ya abolida la institución de la que traía causa en el pasado.

9 Casanova Todolí, U., "La Peste de 1652: problemas de cuantificación y gasto», Revista d'Estudis Balearics, n. ${ }^{\circ} 21,(1986)$, pp. 51-62.

10 Archivo del Reino de Mallorca (=ARM): Real Audiencia (=RA) 663/28. 
Posteriormente el Ayuntamiento de Palma suplicó que se mantuviese el criterio de anualidad anterior, y la Real Audiencia, reunida en acuerdo ordinario, lo concedió, aunque cambiando el sistema de elección. Respetando el criterio estamental figuraron como sujetos aptos para ser designados Morberos los siguientes: D. Fernando Gual y Moix (morbero militar), D. Antonio Comellas (morbero ciudadano) y Gabriel Cañellas (morbero mercader). El juramento de los designados se llevó a cabo ante el Capitán General en fecha 16 de mayo de 1721. Al renovarse un año después quienes debían cubrir el oficio de Morberos los nuevos designados fueron: $D$. Agustín Sureda, D. Jerónimo Alemany y Francisco Planes, Capitán de Mar. Sin embargo, éste último se excusó, alegando su crecida edad, y su lugar fue ocupado por Antonio Planes. En los juramentos prestados se incluía la fórmula de que los Morberos designados observasen, "todos los Privilegios, Franquezas, Capítulos y Ordinaciones que vuestros antecesores han acostumbrado tener y guardar ", lo que establece una línea de continuidad en el desempeño de sus funciones, aunque teniendo en cuenta el nuevo marco institucional.

La dinámica de la actuación de los morberos se iniciaba con la arribada de una embarcación al puerto de Palma. Una vez avistada su llegada por los encargados del puerto, se ponía en conocimiento de los morberos - los cuales, auxiliados de Médico y Cirujano del Morbo interrogaban al Capitán, tripulantes y pasajeros de la embarcación arribada, indagando su lugar de procedencia y situación sanitaria del mismo, posibles incidencias habidas durante la travesía, cargamento de la nave, estado de salud de los ocupantes del barco y cuantos detalles se considerasen relevantes para prevenir el contagio. Se daba cuenta de las actuaciones practicadas al Ayuntamiento, a la Real Audiencia y al Capitán General, señalándose la cuarentena correspondiente para las personas y mercancías, que según los casos, se realizaba en la propia embarcación o en el lazareto, contando con la presencia de los oportunos vigilantes, encargados de impedir cualquier comunicación con el exterior mientras durase la cuarentena. Cuando el plazo estaba a punto de expirar, se ponía en conocimiento del Capitán General, recabando su aprobación para conceder la libre entrada y comercio, que era concedida a reserva de que no hubiese novedad. Entonces, en presencia de Morbero, acompañado del Médico y del Cirujano del Morbo, se interrogaba a los guardias de la salud sobre posibles incidencias, y caso de responder que no habían existido, se examinaba el estado sanitario de los tripulantes y pasajeros. Si el Médico y el Cirujano del Morbo lo consideraban satisfactorio se procedía a conceder libre práctica y comercio, pudiéndose dar el caso de que lo obtuviese el personal de la embarcación mientras las mercancías debían permanecer en cuarentena 
por más tiempo. Esta situación incomodaba por las molestias que suponía para el tráfico comercial y los gastos que acarreaba, si bien la documentación examinada suele ser parca en este último extremo. Todas las actuaciones citadas, debidamente documentadas, formaban los llamados Autos de Morbería, auténticos expedientes donde se reflejaban las actuaciones administrativas practicadas en relación a la normativa de prevención sanitaria vigente.

En cambio, no se ha localizado una masa documental unificada bajo la denominación de Junta de Morberos, ni otros documentos que permitan conocer la evolución interna de esta institución durante el periodo de referencia. No obstante, se ha localizado un documento emitido por la Junta Suprema de Sanidad (creada en octubre de 1720 a consecuencia de la peste de Marsella y con sede en Madrid), fechado en Madrid el 18 de octubre de 1756, cuyo contenido resulta de suma importancia, en cuanto señala la transición de la Junta de Morberos a la Diputación de Sanidad en Mallorca a mediados del siglo XVIII.

En 1756, el Capitán General de Mallorca, D. Luis de Albelda y Cairo, dirigió una representación acompañada de varios documentos a la Junta Suprema de Sanidad, en relación a unas actuaciones llevadas a cabo por la Junta de Morbería de Mallorca sobre una galeota de moros apresada y una embarcación de diez esclavos fugitivos de Argel. No se han encontrado más menciones de dichas embarcaciones, ni de las discrepancias que obligaron a recurrir a la Junta Suprema de Sanidad, pero en la respuesta de la Suprema se describe con todo lujo de detalles cómo ha llegado a su conocimiento que la Junta de Morbería de Mallorca estaba integrada por un caballero, un mercader menorquín y un francés, lo cual atestigua la persistencia del oficio de Morberos en Mallorca aunque con dos morberos que no eran mallorquines. Desde Madrid se considera todo esto "contrario a la práctica dispuesta para todos los demás puertos del Reyno" (en referencia a España), aparte del inconveniente que supone la presencia de extranjeros en tales organismos y, en su consecuencia, acuerda que "se extinga desde luego la Junta llamada de Morbería, que hay al presente, y en lugar de ella se establezca una Diputación de Sanidad, compuesta por los Regidores de esa Ciudad, y si estos fuesen muchos de los que sean más hábiles y versados en estos asuntos, los cuales, presididos por el Corregidor, deberán entender y cuidar inmediatamente de todos los asuntos tocantes al resguardo de la Salud pública" ${ }^{11}$.

i ARM., RA XLVH/24 
Los regidores que integraban la nueva Diputación de Sanidad lo hacían con carácter vitalicio y en caso de que quedase alguna plaza vacante por muerte, enfermedad $u$ otro motivo se nombraría otro regidor en su lugar, previa noticia y aprobación de la Junta Suprema de Sanidad, lo que implicaba un mayor control desde Madrid en el nivel que nos ocupa.

Los diputados y el corregidor no cobrarían sueldo alguno por el desempeño de sus funciones, debiéndose turnar los primeros regularmente en el muelle para asistir a los asuntos de Sanidad. Dicha Diputación debería contar con los servicios de un médico, un cirujano y los subalternos necesarios, disponiendo, además, de una embarcación para fines sanitarios con su correspondiente patrón y tripulantes. El coste de dicho personal sería sufragado mediante las cantidades que se percibiesen por los derechos de visita sobre todas las embarcaciones extranjeras arribadas al puerto de Palma y las cantidades recaudadas aparte en caso de cuarentena.

Por último, se señala cómo esta Diputación de Sanidad puede recabar el auxilio del Capitán General, ya fuese en tropas o en asesoramiento, en cuyo último caso éste presidiría y formaría otra Junta de Ministros de la Audiencia para determinar lo más conveniente. En la práctica se resaltan los ejemplos de Barcelona y Valencia, sugiriéndose entrar en comunicación con la primera para obtener más información.

Las anteriores disposiciones suponen un cambio decisivo en la institución local dotada de funciones en materia de prevención sanitaria, la Junta de Morberos desaparece y es sustituida por la Diputación de Sanidad. Dicha Diputación permanece subordinada a los criterios de la Junta Suprema de Sanidad, la cual marca los criterios fundamentales de la misma y de quienes la deben integrar, abandonando el criterio de anualidad por el ejercicio vitalicio de las funciones por parte de sus miembros. Distinto será el caso de Menorca en donde la Morbería perduró hasta $1803^{12}$.

\section{LA PESTE DE MARSELLA (1720-1723)}

Antes de hablar de la aparición de la peste en Marsella en 1720, y las medidas de prevención sanitaria que se aplicaron en Mallorca para prevenir su contagio, creo conveniente referirme a la importancia de Marsella como enclave comercial de primer orden en el ámbito mediterráneo.

LOPEz NADAL, G., "La Sanidad marítima menorquina anterior al funcionamiento del Lazareto de Mahón", en Menorca en la historia de la Sanidad. Madrid, 1987, pp. 83-108. 
Ya durante el siglo XVII Marsella canalizaba el flujo de mercancías procedentes del Norte de África, convirtiéndose de este modo en un valioso y obligado intermediario comercial para los mallorquines, dadas las relaciones comerciales casi inexistentes mantenidas entre Mallorca y el Norte de Africa. Marsella no sólo adquiría cereales, cueros y cera, sino también productos del Mediterráneo Oriental («Levante»).

No sólo jugaba en favor de Marsella su papel como fuente apta para suministrar los cereales que necesitaba el mercado mallorquín, sino también su capacidad de exportar textiles y otras manufacturas, de los que había gran demanda. Además, Marsella, situada en la costa provenzal, se beneficiaba de su particular proximidad geográfica a Mallorca y del hecho que desde alli partía una ruta en dirección Este hacia Génova-Livorno y el Mediterráneo Oriental, y otra en dirección Oeste hacia los puertos atlánticos, sin olvidar su proximidad a Barcelona ${ }^{13}$.

Tradicionalmente Mallorca ha sido deficitaria en la producción de cereales, necesitando importarlos para asegurar su propio consumo, y los siglos XVII y XVIII no constituyen una excepción en este aspecto. Las exportaciones mallorquinas se basaban principalmente en el aceite ${ }^{14}$, intentando compensar una balanza comercial muchas veces deficitaria. Marsella jugaba un papel de primer orden en estos intercambios comerciales, teniendo en cuenta que el aceite mallorquín no se consideraba tan refinado como otros aceites y por ello no se destinaba tanto al consumo alimenticio como a usos industriales. A principios del siglo xvIII el tráfico de cabotaje era llevado a cabo por embarcaciones de pabellón francés, tipo "tartana", pero a partir de 1730 van siendo sustituidas por navegantes mallorquines que emplean el jabeque o xabec. El jabeque es una embarcación de silueta airosa, de 80 a 120 toneladas, que emplea tres palos con vela latina, fina, resistente y rápida, y tripulación de 10-12 hombres, siendo también utilizada por los corsarios mallorquines. De esta manera progresivamente el control de la ruta marítima entre Marsella y Mallorca quedaría en manos de embarcaciones mallorquinas ${ }^{15}$.

13 Bibiloni Amengual, A., El comerç exterior..., pp. 278-280.

14 JUAN VIDAL, J., "La producción de aceite en Mallorca durante la Edad Moderna y su papel en la economia mallorquina", en Bolleti de la Societat Arqueològica Luliana, vol. 27 (1980), pp. 519-552 y, "Crisis de subsistències i aprovisionament blader de Mallorca durarit el segle XVIII", Randa, n. ${ }^{\circ} 26,(1990)$, pp. 103-132.

15 Boulanger, P., "Marsella y el comerç dels olis de les Balears al segle XvIlı, en El Regne de Mallorca y el Sud francès (IV Jornades d Estudis Històrics Locals). Palma, 1986, pp. 59-67. Y también, Alonso Pérez, M., "Relaciones comerciales entre Mallorca y los Puertos del Sur de Fran cia al final del Antiguo Régimen", en El Regne de Mallorca y e' Sud francès (IV Jornades d'Estudis Històrics Locals). Palma. 1986, pp. 69-80. 
A mediados de julio de 1720 la peste se introdujo en Marsella por omitirse las medidas sanitarias de rigor al descargar un barco infectado procedente de Levante. La importancia comercial de Marsella supuso que las repercusiones no sólo se extendiesen al espacio mediterráneo, siendo éste el más afectado, sino que alcanzasen también el tráfico atlántico ${ }^{16}$. La alarma generada por la aparición de la peste en Marsella llegó hasta Mallorca y, nada más conocerse la noticia, el Capitán General publicó un Decreto, fechado en 7 de agosto de 1720, ordenando a las autoridades municipales (bayles) de los distintos pueblos o villas que controlasen la vigilancia del personal de guardia situado en torres y atalayas. Estas construcciones esparcidas por todo el litoral de la isla, con su correspondiente dotación de guardias, tenían como misión controlar cualquier posible peligro procedente del mar (piratas, corsarios enemigos), y dar la alarma para adoptar las medidas necesarias. Formaban la estructura de defensa costera, y ahora, con motivo de la peste de 1720 , también formarán una especie de cordón sanitario alrededor de Mallorca, con misiones de observación y de prevención del desembarco de cualquier embarcación venida de fuera, "porque a nadie se ha de admitir sino en el Puerto principal de Palma" ${ }^{17}$. Se trata de una centralización del control de las embarcaciones arribadas, que deberán concentrarse en un solo puerto, guardando similitud tal medida con lo dispuesto en Cataluña a favor del puerto de Barcelona. Tal medida, al concentrar el tráfico en un solo puerto beneficiaba a éste en perjuicio de los restantes puertos del litoral que pudiesen competir con aquél ${ }^{18}$.

Con posterioridad al Decreto anterior se recibió en Mallorca la Real Provisión, dada en Madrid y fechada el 3 de agosto de 1720, "que ordena reconocer y visitar todas las embarcaciones venidas del Mediterráneo a fin de averiguar su lugar de procedencia y escalas realizadas" "19. A medida que se iba conociendo cómo se agravaba el contagio en Marsella, las medidas de prevención se irían endureciendo, lo que supone que la normativa vigente no formaba un cuerpo cerrado desde el primer momento, sino que iba evolucionando al compás de los acontecimientos, intentando no verse nunca desbordada y articulando una respuesta flexible a los mismos. Por

16 Palop, J. M., Hambre y lucha antifeudal (Las crisis de subsistencias en Valencia. Siglo xviII). Madrid, 1977, p. 41.

ARM., DI 1720 .

18 Martín Corrales, E., "La proyección mediterránea del sistema portuario español: siglos XVI-XVIII", en Puertos y Sistemas Portuarios (siglos XVI-XX). Madrid, 1996. pp. 143-165. Del mismo autor, "Sobre Sanidad y Pesca en la Cataluña del siglo xvlı», Revista Estudis d'História Económica. (1988), pp. 45-64.

19 ARM., DI 1720. 
esta razón la organización sanitaria ampliará su campo de acción, buscando prevenir cualquier posibilidad de contagio, ya fuese directa o indirecta, lo que redundará en disponer un exhaustivo control e inspección de las embarcaciones arribadas al puerto de Palma, sin más excepciones que las expresamente autorizadas. Todo ello suponía sujetar el flujo del tráfico mercantil a la normativa de prevención sanitaria vigente, con las molestias, demoras y gastos que acarreaba. El 19 de agosto de 1720 otra Real Provisión, dada en Madrid, "prohibe el comercio a las personas y géneros que vinieren de Marsella, y se prohibe absolutamente la entrada de todos los géneros y ropas, que vinieren de los Puertos que Francia tiene en el Mediterráneo" ${ }^{20}$. La prohibición anterior se extenderá a los barcos procedentes de Italia y Levante que hubiesen hecho escala en Marsella o comerciado con ella.

Para garantizar el control de las embarcaciones arribadas dicha Real Provisión ordena que en los puertos se pongan barcos de la guarda de la salud, así como personal competente con igual fin en los barcos de las aduanas. El Ayuntamiento de Palma quedaba encargado de cumplir dicha orden, debiendo contratar y financiar a tal efecto las correspondientes embarcaciones con el personal necesario, y ello en unas circunstancias económicas desfavorables. Pese a ello, el Ayuntamiento en sesión celebrada el 2 de septiembre de 1720 acordó fletar tres barcos para guardar las costas, "y que en cada uno de ellos haya seis marineros y un muchacho con un superintendente o guarda de la salud", debiendo el Capitán General dotar a cada embarcación con un oficial y dos soldados. Asimismo el Ayuntamiento proporcionaría, "como ayuda de costa, cuatro reales de plata a cada oficial, un real de plata al día a cada soldado y tres reales de plata al superintendente ${ }^{21}$. Por Real Provisión de fecha 7 de septiembre de 1720 «se prohibe el comercio con las Provincias de la Provenza, Languedoc, León, Niza y Mentón, condenándolas por sospechosas de contagio", y por Real-Orden de igual fecha se prohibe admitir en ningún puerto español a los navíos procedentes de Alexandreta o de Levante, por la creencia de que la peste se había introducido en Marsella desde aquellas regiones ${ }^{22}$.

Paralelamente se refuerza la lucha contra el contrabando, ya que se considera que la introducción clandestina de géneros en época de epidemia genera un grave riesgo de contagio. Ya no se trata sólo de que se

\footnotetext{
ARM., DI 1720 .

Archivo Municipal de Palma (= AMP), Libro de Actas, 1720, Fol. 101-V.

ARM., DI 1720 .
} 
vean defraudados los derechos fiscales, "sino que el contrabando violaba todas y cada una de las disposiciones sanitarias", lo que motiva su persecución por las instituciones fiscales y sanitarias simultáneamente con los posibles conflictos de jurisdicción que ello pueda suponer ${ }^{23}$. Preocupa, sobre todo, a las autoridades sanitarias la introducción clandestina de géneros sospechosos y, según la Real Provisión de 11 de septiembre de 1720, se ordena incautarse de cualquier género que venga sin despacho de Sanidad seguro y quemarlo, añadiéndose como menos principal el cargo de fraude de las Rentas Reales contra los introductores. Para estimular el celo de los delatores se dispone que si fuesen cómplices de la introducción de géneros procedentes de lugares sospechosos su delación les supondría el perdón y, no siéndolo recibirían la mitad del valor de las mercancías. Si los géneros introducidos fraudulentamente no fuesen sospechosos de contagio la pena era de cinco años de galeras, obteniendo el perdón el cómplice delator y, no siendo cómplice un tercio del valor de las mercancías.

En caso de que el contrabando se produjese acercándose a embarcaciones arribadas al puerto de Palma antes de ser visitadas por las autoridades sanitarias o ya guardando cuarentena se impone la pena de muerte en la horca. Y se señala igual pena para quienes hubiesen infringido la cuarentena ${ }^{24}$. Son disposiciones rigurosas que persiguen ante todo mantener el riguroso aislamiento y control sanitario, evitando que se produzca el contrabando entendido como actuación ilegal contraria.

Para evitar que sean burladas las disposiciones de control establecidas, se ordena que los barcos que vayan desde Palma a distintos puntos del litoral mallorquín para conducir víveres necesiten, antes de partir, permiso del Capitán General, especificando el lugar de destino, del que no podían apartarse excepto por tempestad o accidente, poniéndolo en tal caso en conocimiento de las autoridades del lugar de arribada forzosa, cuyo testimonio debían traer de vuelta como justificante, so pena de perder el barco, la carga y ser condenados a cuatro años de galeras. Tampoco los pescadores escapan a la atención de las autoridades, y asi se les prohibe faenar a distancia tal que no puedan ser vistos desde la costa, debiendo volver al puerto por la noche y, caso de tener que pescar de noche, comunicarlo a las autoridades.

23 Martin Corrales, E., "El contrabando en el litoral catalán en la primera mitad del siglo XVIII (1720-1759)", en El comerç alternatiu: corsarisme i contraban (ss. XV-XVIII) VIII Jornades d'Estudis Històrics Locais. Palma, 1990, pp. 329-345. Del mismo autor, "El contrabando en el litoral catalán

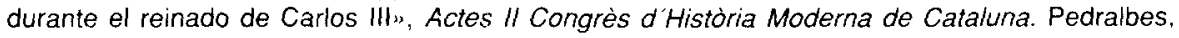
1988, 8-1, pp. 485-494.

24 ARM., DI 1720. 
Así, el panorama a mediados de septiembre de 1720 , esto es a los tres meses de haberse iniciado la epidemia de Marsella, ofrece un litoral mallorquín controlado mediante vigías y barcos de patrulla, la centralización del tráfico marítimo en el puerto de Palma y la incomunicación absoluta con los puertos del sur de Francia, Marsella incluida, y Levante. Sin embargo, las necesidades de abastecimiento no desaparecen y el tráfico mercantil se orienta desde y hacia los puertos italianos, que aprovechan la favorable coyuntura. El incremento de este tráfico también será objeto de atención por parte de las autoridades españolas, que dictarán una serie de medidas para evitar cualquier riesgo. En tal sentido, la Real Provisión de 18 de septiembre de 1720 establece que, aunque las embarcaciones vengan derechas desde Italia, único comercio permitido con los puertos de Levante, aportando derrotero del viaje y testimonios de Sanidad, también deben traer certificados de origen de los géneros transportados, faltando los cuales no serian admitidas.

El ámbito de las medidas de prevención ya no se circunscribe al Mediterráneo, sino que también se acentúan las limitaciones al comercio internacional. Así, a finales de octubre de 1720 sólo se permite la entrada de los navios sin mercancías procedentes de los puertos oceánicos de Francia, aunque con la excepción de los barcos con cargo de bacalao que vengan derechos desde Terranova. Los barcos de otros países del Norte (ingleses, holandeses) son admitidos, en cuanto a personas y ropas, siempre que puedan demostrar que no se han mezclado con franceses.

Mientras tanto la peste continuaba recrudeciéndose en Marsella lo que motivaba un endurecimiento de las medidas sanitarias dictadas por las autoridades españolas y, las consiguientes restricciones al tráfico comercial ${ }^{25}$. A principios de diciembre de 1720 se amplían las restricciones vigentes hasta el Piamonte, y mediante Real Provisión de 13 de diciembre de dicho año se prohibe admitir a los navíos franceses procedentes de Levante, incluso llevando testimonio de que venían de puertos italianos, en lo relativo a ropas y mercaderías, debiendo someterse las personas a cuarentena; igual medida se ordenaba para los barcos de bandera genovesa, con la única excepción de las embarcaciones de esta bandera venidas directamente desde Génova por considerarse puerto seguro.

Sin embargo, la medida más grave consistía en la prohibición de comerciar con todos los navíos «que vinieren con mercancias de las Islas del

25 Mederic de Gasquet: Contribuiton à létude de la peste, d'après une relation inédite de l'épidemie de Marseille en 1720, suivi des moyens de préservation employés a cette époque. Montpellier, 1921. Y también, C. Carrière, M. Courdoufie y F Rebuffar, Marseille ville morte. La peste de 1720. Marseille. 1988. 
Mediterráneo", de modo que trayendo testimonios de Sanidad sólo debían ser admitidas las personas a cuarentena ${ }^{26}$. Esta medida equivalía en la práctica a yugular el tráfico comercial de Mallorca e Ibiza.

Si a ello añadimos la Ordenanza emitida por el Marqués de Casa-Fuerte el 27 de noviembre de 1720 , donde se regulaba el sistema de guardias continuas, disponiendo 129 puestos costeros en la isla de Mallorca con 221 hombres armados como vigilantes y 19 puestos en el distrito de Palma con 38 vigilantes, no es difícil llegar a la conclusión de que la prevención sanitaria podia desembocar en un estricto bloqueo. En esta Ordenanza se establecian las necesidades en vigilantes de cada villa o pueblo costero. Cada municipio, ya fuese costero o no, debía aportar un número de hombres en proporción con sus respectivos habitantes. Las guardias duraban tres días y entraban en ellas todos los vecinos mayores de 16 años y menores de 65, excepto los enfermos y lisiados. Las autoridades municipales se encargaban de hacer las rondas y controlar los puestos. El designado para una guardia podía enviar un sustituto, que debía contar con la aprobación del municipio de procedencia y del lugar de destino, sin que dicho sustituto pudiese cobrar más de tres sueldos de moneda mallorquina al día. A los guardias se les entregaba pólvora, balas y armas, que a su vez debian entregar a los relevos, salvo la munición gastada para impedir desembarcos no autorizados $u$ otras incidencias.

En el caso de Palma se procedía a adjudicar a cada parroquia el número de hombres que debía de aportar para las guardias, teniendo en cuenta el número de vecinos. La de Santa Eulalia con 2360 vecinos, debía dar 11 hombres, mientras que la de la Catedral con 144 vecinos, sólo daría un hombre. El cumplimiento de cada parroquia era supervisado por un regidor, que podía ayudarse con personas de su confianza. Los encargados de hacer las rondas de los puestos de guardia eran escogidos entre sujetos hábiles de los estamentos de los caballeros y de los ciudadanos.

Este Reglamento de Guardias, de acuerdo con la Ordenanza aludida, entró en vigor el 25 de noviembre de 1720 en la Isla de Mallorca, excepto en Palma, donde se aplicó a partir del 1 de diciembre ${ }^{27}$.

No finaliza este año de 1720 sin otra Real Provisión, fechada el 18 de diciembre, que admite las embarcaciones procedentes de Portugal y Brasil, mediando visita, y siempre que no traigan géneros franceses.

Un ejemplo práctico de aplicación de las normas de prevención sanitaria de 1720 en Mallorca se encuentra en la documentación del Marqués de

\footnotetext{
26 ARM., DI 1720.
}

27 ARM., DI 1720 . 
Casa-Fuerte que se conserva en el Archivo del Reino de Mallorca. En fecha 14 de noviembre de 1720 el Capitán General amonestó al corregidor y al Ayuntamiento de Palma por haber admitido la balandra del capitán Pedro Roberto, inglés, lo que no se llevó a cabo en el puerto de Barcelona "por el legítimo motivo de haber salido de Orán sin Boleta de Sanidad, ni póliza de cargo, y considerarse aquel puerto no limpio y sospechoso de comunicación con los de Francia", ordenando, en consecuencia, su inmediata partida ${ }^{28}$.

Así lo ejecutaron las autoridades municipales, aunque alegaron los motivos por los que había sido admitida en Palma. De su examen se obtiene valiosa información sobre el modo en que dichas autoridades interpretaron los criterios de admisión y documentación requerida en este caso concreto. Así, interrogado a su llegada el capitán de dicha balandra, con cargo de trigo y cebada, manifestó que en Orán no había riesgo de epidemia y aportó una certificación del cónsul inglés en aquella plaza en tal sentido. Para los responsables municipales tales certificaciones consulares equivalían a la patente de sanidad cuando los navíos procedian del Norte de Africa. Por consiguiente, la balandra fue puesta en cuarentena, y al ser visitada por segunda vez en presencia del médico y el cirujano del Morbo se encontró que la tripulación gozaba de buena salud, siendo admitida a comercio. El capitán podía introducir su carga, pero al no encontrar el beneficio esperado, pidió y obtuvo de las autoridades municipales patente de sanidad para Barcelona, donde no fue admitida. La decisión de Barcelona causó extrañeza en los responsables municipales pues, al fin y al cabo, la balandra procedía de Palma con patente de sanidad emitida en esta última plaza, lo cual ilustra la discrepancia de pareceres entre los mismos puertos españoles a la hora de aplicar las medidas de control sanitario. El Capitán General como autoridad superior de la isla hará suyo el criterio de Barcelona en este asunto, teniendo su dictamen carácter definitivo, con el consiguiente disgusto de las autoridades mallorquinas ${ }^{29}$.

En 1721, por Carta-Orden de 18 de febrero, Mallorca e Ibiza quedan excluidas de la prohibición general de comercio con las islas del Mediterráneo contemplada en la Real Provisión de 13 de diciembre del año anterior. Erı cambio se prohibe la recepción de granos de fuera de España por el riesgo de contagio. Las deficitarias cosechas habidas en Mallorca en 1721 motivaron que el Ayuntamiento de Palma solicitase permiso para im. portar cereales de sus proveedores tradicionales como Génova, Cerdeña y

29 ARM., Real Patrimonio (=RP) 4199.

29 ARM., RP 4199. 
el Norte de Africa, lo que le fue concedido en agosto de 1721, pudiendo abastecerse de trigo del puerto de Génova y de Cerdeña ${ }^{30}$.

En Carta-Orden de fecha 21 de abril de 1721 se advirtió que no estaba prohibido el comercio con Livorno ni con los restantes puertos de Italia, pese a las disposiciones de diciembre del año anterior. Es decir, no se consideraba que en aquellos puertos existiese contagio, sino que no se guardaban las precauciones necesarias para evitar mezclar géneros sospechosos con otros que no lo eran. Se permitía así a los vecinos de Mallorca despachar los frutos de la Isla (sobre todo el aceite) «a los Navíos que procedan de los puertos de las islas de Italia, Riberas de Génova y otros Puertos donde es notorio se goza de Sanidad", aunque extremando las precauciones y recibiendo el importe "con moneda pasada por vinagre, como se practica en la entrega de víveres a los navíos que se despiden» ${ }^{31}$.

Un Auto de Morberia fechado el 10 de abril de 1721 da cuenta de la llegada a Palma del navío francés San Antonio, con carga de anís, esparto y productos de droguería, procedente de Alicante. Examinado por los morberos, su procedencia de un puerto español y el hecho de patente y certificados de los géneros permitió su admisión al comercio, mediando el reconocimiento médico correspondiente ${ }^{32}$.

A finales de abril de 1721 llegaron noticias de que Tolón se había contagiado de la peste, de modo que ante el riesgo de que huyera gente de allí por mar para dirigirse a las costas españolas, se ordenó redoblar la vigilancia, reiterándose las órdenes de centralizar el tráfico comercial en el puerto de Palma de Mallorca.

Por Carta-Orden de 25 de abril de 1721 se excluyeron los navíos de «la Religión de San Juan" de la prohibición de comercio con las islas del Mediterráneo, de modo que, siendo visitados y examinada su documentación pudiesen ser admitidos al comercio con una cuarentena de ocho días. Beneficio que se extendió a los barcos procedentes de la isla de Malta y que fuesen propios de malteses.

El 14 de noviembre de 1721 se publicó en Palma de Mallorca la Real Cédula de 10 de octubre de dicho año en donde se recopilaba toda la normativa vigente para prevención del contagio de Marsella. Constituye un texto fundamental en cuanto servirá de base normativa para aplicar las medidas de

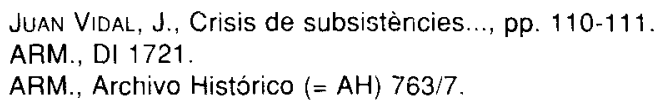


prevención ante las epidemias posteriores que se vayan sucediendo en otros lugares durante el siglo XVIII. Dicho texto contiene una serie de novedades, entre las que destacan la posibilidad de introducir cera y cobre procedentes de Berbería que traigan patente limpia de sanidad, mediando cuarentena de 40 días en el lazareto. Se consideran como patentes más limpias de sanidad las de los cónsules franceses o ingleses, lo que nos recuerda el caso de la balandra inglesa admitida en Palma en 1720 y luego despedida por orden del Capitán General, y las emitidas por los Vicarios de la Redención de cautivos donde los hubiese. Del mismo modo, las embarcaciones que viniesen directamente de Terranova cargadas de bacalao, y de Noruega con pescado salado y maderas, aunque no trajesen patente de sanidad podían ser admitidas tras una cuarentena de diez días. Finalmente se contemplaba la posibilidad de admitir a las embarcaciones que hubiesen salido del puerto de Génova y trajesen bandera francesa "por temor de los Moros" ${ }^{33}$.

Un ejemplo práctico de aplicación de este último supuesto lo proporciona un Auto de Morberia, donde se documenta la llegada al puerto de Palma de una supuesta tartana francesa el 27 de febrero de 1722. Se declaró ante el morbero que procedía de Génova, habiéndose detenido cinco días en Alcudia, y llevando carga de trigo, tabaco y otros géneros, con 14 tripulantes y 4 pasajeros. Ante la disposición de la Real Audiencia de que la embarcación fuese puesta en cuarentena y guardada hasta una resolución del rey, un mercader, Carlos Fontichelli, con intereses en la misma presentó un memorial al Ayuntamiento de Palma y a los morberos. En este memorial hacía constar que en realidad se trataba de genoveses y no de franceses, habiendo usado bandera francesa "como precaución contra los Moros", pues, en realidad, el patrón de dicha embarcación ya habia efectuado otros viajes entre Génova y Palma cargando mercancía por cuenta del suplicante. Comunicada la novedad a la Audiencia por el Ayuntamiento, con expresa mención de la disposición favorable que amparaba este supuesto según la Recopilación sanitaria de 1721, se admitió que dicha tartana fuese admitida en cuarentena, según competencias del Ayuntamiento y morberos ${ }^{34}$. En cambio, el 7 de febrero de 1722 el Capitán General amonestó a las autoridades municipales por haber admitido un barco francés, procedente de Génova ${ }^{35}$.

La necesidad de mantener operativos a los encargados de llevar a cabo las disposiciones anteriores suponía unos gastos cuyo peso principal recaía sobre las autoridades municipales, que es casi tanto como decir el

\footnotetext{
ARM., DI 1721.

ARM., Real Audiencia (= RA) 664/26

ARM., RP 4199.
} 
Ayuntamiento de Palma, ya que en esta ciudad se centralizaba el control de las medidas de prevención vigentes. La obligación de afrontar tales gastos pesará gravemente sobre el Ayuntamiento de Palma durante todo el tiempo de la epidemia de Marsella, e incluso después, ya que la reapertura del tráfico marítimo con los puertos del sur de Francia no supondrá la extinción automática de las obligaciones anteriores.

Ya el 3 de septiembre de 1720 consta haberse celebrado una sesión extraordinaria en el Ayuntamiento, donde se acordó aprobar «la resolución capitular de 31 de agosto pasado sobre el préstamo de la Tabla y Talla para gastos del contagio" ${ }^{36}$. La cantidad solicitada para dichos gastos era de 2.000 libras (en moneda mallorquina), y con ocasión de tener que adelantar cantidades para pagos del personal de los barcos «para guarda de la salud" el pagador recibió 300 libras.

El 12 de agosto de 1722 nos encontramos con un documento dirigido desde el Ayuntamiento a las máximas autoridades, señalando las penurias que se experimentan para hacer frente a los pagos en materia de prevención sanitaria. En relación fechada cuatro días antes se manifiesta que los exactores eclesiásticos seculares y los forenses adeudan por las dos tallas de cuatro mil libras para precaución del contagio, 2.365 libras, 4 sueldos y 2 dineros ${ }^{37}$.

A finales de octubre de 1722 el Ayuntamiento de Palma, con la Junta de la Consignación y Síndicos Forenses, acuerdan la necesidad de otra talla de 2.000 libras para gastos de prevención del contagio, pese a los continuos repartimientos y tallas "que actualmente se cobran, de que queda muy probado el público". En este último comentario se traduce la sensación de agobio fiscal de quienes contribuyen a pagar dichas tallas. Si a ello añadimos la escasez de la cosecha de trigo de 1722, entenderemos mejor la nota de desaliento de las autoridades municipales. Puesto dicho acuerdo en conocimiento del Capitán General para su aprobación, éste ordena en fecha 3 de noviembre, que se revisen las cuentas de todos los exactores de las tallas para el contagio.

En mayo de 1723 el Ayuntamiento acude de nuevo a la Audiencia al precisar que se necesitan «300 libras mensuales para poder acudir a los gastos que se van haciendo para la precaución del contagio de Marsella", no dando de si la actual talla de 2.000 libras "más que 200 libras al mes». En consecuencia, la autoridad municipal solicita que el Real Acuer-

3ô AMP., Libro de Actas. 1720. Fol. 102-V.

37 ARM., RA 664/5. 
do le conceda autorización para solicitar un préstamo de 1.000 libras, lo que no se acepta, ordenándole en cambio que socorra al personal de vigilancia con el caudal existente de 450 libras, 9 sueldos y 6 dineros, lo que cubría los gastos de un mes escaso ${ }^{38}$.

Según una relación adjunta donde se establecían las cantidades adeudadas a los cinco barcos de la Salud y demás, desde el 9 de abril de 1723 hasta el 6 de agosto de dicho año corresponderían «884 libras a los cuatro Barcos de la Salud que rondan la Isla, 276 libras y 5 sueldos al Barco situado en el cabo del muelle, 55 libras al Sargento Mayor de la plaza de Palma encargado de reconocer a las embarcaciones que vengan de fuera, y finalmente, 46 libras a Pedro Juan Bisbal, como guardia de la casita del cabo del muelle y sellador de las ropas venidas de fuera, lo que da un total de 1.261 libras y cinco sueldos" ${ }^{39}$.

El 18 de junio de 1723, mediante Real Cédula, se volvió a abrir el comercio con Francia. Una de las primeras medidas consistió en disminuir los efectivos dedicados a guardar las costas «para prevención de la salud pública", quitándose los barcos de guardia y manteniéndose sólo los barcos de aduanas, las visitas de navíos «y lo demás que se practica por necesaria precaución». Eran admitidos los navíos franceses procedentes de puertos oceánicos sin haber cargado mercancías sospechosas sin mediar cuarentena; para los provenientes de los puertos de Provenza, tras ser visitados y reconocidos, se imponía una cuarentena de diez días a las personas y géneros no susceptibles de contagio, mientras que las ropas y los restantes géneros debían sufrir una cuarentena de cuarenta días en los lazaretos antes de ser admitidos al comercio. No se debían admitir navíos procedentes de Levante, excepto de Venecia, sin que constase haber sido admitidos en otro puerto de Italia, en lo tocante a géneros susceptibles de contagio, como ropas, mientras las personas y los granos podian admitirse con los testimonios de sanidad limpios. En cuanto a los barcos procedentes del Languedoc debían hacer veinte días de cuarentena.

Se prohibía admitir el algodón en rama procedente de los puertos del Mediterráneo, pero sí él hilado y tejido que hubiese hecho cuarentena y admitido en los puertos de Italia, Sicilia, Cerdeña y Malta ${ }^{40}$.

Sin embargo, una Orden del Comandante General de Mallorca, de 4 de julio de 1723, mantenía el papel exclusivo del puerto de Palma, reserván-

\footnotetext{
ARM., RA 666/33.

A.RM., RA 666/33.

ARM., DI 1723.
} 
dole «dar práctica a todo género de embarcaciones que vengan de fuera del Reino».

Ciertamente, a principios de julio de 1723 se retiraron los barcos para guarda de la salud en Mallorca, con lo que la previsión de gastos hecha hasta agosto de dicho año no tuvo, en principio, razón de ser. No obstante, este mismo hecho documenta las dificultades que se experimentaron para hacer frente a los gastos extraordinarios para prevención del contagio. Pese a la existencia de futuros estados de alarma en años posteriores, puede decirse que este periodo fue el más crítico y el que sentó las bases de futuras actuaciones, como veremos a continuación.

\section{LAS EPIDEMIAS INTERMEDIAS (1723-1742)}

A lo largo de los años que van desde 1723 hasta 1742, esto es, en el intervalo entre la peste de Marsella y la de Messina, nuevas alarmas se suceden en diversas zonas del Mediterráneo Oriental ("Levante") y del Norte de Africa, exigiendo la atención de las autoridades para evitar el peligro de contagio. Sin embargo, el tráfico mercantil directo hacia Mallorca desde Levante es escaso, por lo que los efectos de tales medidas también son menores aunque existan.

Apenas tres años después de la peste de Marsella se conoce la noticia de que se hallan afectadas por dicho mal contagioso las localidades de Esmirna y Constantinopla, entre otras. En consecuencia, se dicta, para prevenir posibles contagios, la Real Provisión de I de noviembre de 1726, publicada en Palma el día 24 de dicho mes, en la cual se prohibe todo comercio directo con los puertos de Levante, admitiéndose solamente las embarcaciones procedentes de puertos italianos considerados seguros como Génova, Livorno y Malta, con los certificados correspondientes.

En 1728 vuelve la preocupación a las autoridades españolas ante las noticias de estar contagiadas las islas de Zante, Morea y Corfú. Reaccionan con la Real Provisión de 8 de mayo de 1728, que prohibe admitir al comercio a las personas, géneros y embarcaciones procedentes de Levante, traigan o no certificados. Sólo se admiten las embarcaciones procedentes del puerto principal de Génova, que aporten testimonios auténticos de sus cargas, legalizados por el cónsul de España en aquella Plaza. Finalmente, se prohibe absolutamente el comercio con el Norte de Africa, sin exceptuarse la cera y el cobre como antes, y sin que tampoco puedan ser admitidos los granos que vengan de fuera.

Esta última prohibición afectó directamente a Mallorca, máxime si pensamos que durante 1728 la cosecha volvió a ser escasa. No obs- 
tante, durante dicho año entraron embarcaciones con cereales de diferentes lugares, continuando las importaciones durante los primeros meses de 1729, incluso desde lugares como Orán y Argel ${ }^{41}$. El tráfico entre los puertos del Norte de Africa y Mallorca se realizaba, principalmente, a bordo de buques ingleses y franceses, apareciendo documentadas algunas visitas de control sanitario en los correspondientes Autos de Morbería.

A principios de junio de 1733 se difunde la noticia de una epidemia de peste en la localidad de Trípoli, en Berbería, por lo que se reitera la prohibición de comerciar con Africa. Por último, a finales de mayo de 1740, según carta de un religioso que asiste a los cristianos en Argel, se comunica que la peste se había introducido en aquella ciudad a través de una embarcación francesa que había llegado de Esmirna infectada, sin que se hubiesen adoptado las precauciones adecuadas. Una vez más vuelven a activarse los dispositivos de vigilancia, recordando la epidemia de 1720 , y así se emite una Instrucción que consta de treinta apartados sobre medidas de prevención sanitaria, y que dispone, entre otras cosas, el control de las embarcaciones en el puerto de Palma, una vigilancia costera rigurosa y la prohibición de admitir a las embarcaciones procedentes de los lugares infectados ${ }^{42}$.

Como ejemplo práctico de las disposiciones de este periodo disponemos de un Auto de Morbería, donde se describe la llegada de una tartana francesa al puerto de Palma, procedente de Argel, el 30 de noviembre de 1723. Llevaba como cargamento una partida de lana, otra de cera, otra de cobre y otra de sombreros, así como un león y una zorra para entregar al Capitán General de Mallorca (lo que motivaba su escala en Palma), pues el resto de las mercancías iban destinadas a Marsella, viajando a bordo 9 tripulantes y 5 pasajeros. Aportaba patente y certificado del cónsul francés en Argel.

El patrón de la tartana, a preguntas de los Morberos, manifestó que en Argel se gozaba de buena salud y que durante el camino había hablado con un barco francés que venía de Levante. El Ayuntamiento de Palma, teniendo en cuenta el certificado del cónsul de Francia en Argel y otro de un religioso Administrador de los Hospitales de la Santísima Trinidad, sobre la buena situación sanitaria en Argel, resolvió permitir el desembarco y cuarentena de la cera, el cobre, el león y la zorra, así como la de los pasaje-

41 JUAN VIDAL, J., Crisis de subsistències..., p. 113.

ARM., DI 1740 . 
ros con su ropa de uso personal. Más tarde, el patrón francés envió dos memoriales, pidiendo ser admitido a cuarentena rigurosa, y la Audiencia solicitó, en fecha 6 de diciembre de 1723, se le remitiesen los autos y resoluciones anteriores tomados por la ciudad. Habiendo sido examinados, tres días después el Comandante General amonestó al Ayuntamiento por haber resuelto en este asunto sin haber contado con la intervención de los Morberos, «que según Pragmáticas Reales debían concurrir en la deliberación de la admisión de las embarcaciones", declarando en consecuencia nula y sin efecto la anterior resolución del Ayuntamiento. Entonces el Ayuntamiento decidió convocar una nueva reunión para debatir el asunto, contando con los Morberos, pero haciendo constar, "que la Ciudad se halla en pacífica posesión de resolver en materias de Morbería por si sola, sin asistencia de la Morbería, como son repetidos los ejemplos que lo afianzan y más en los últimos años" ${ }^{43}$.

Convocada dicha reunión, se acordó que, en principio, fuesen admitidos a cuarentena el patrón y su cargo, sometiendo tal resolución a la aprobación del Comandante General. Este ordena que se mantenga la cuarentena acordada mientras se espera resolución del rey. El patrón francés vuelve a enviar otros dos memoriales solicitando la admisión a práctica de la gente, el cobre y la cera, lo que no se acepta. El 8 de enero de 1724 el Comandante General ordenó que sólo fuesen admitidas a cuarentena las personas con su ropa usual. Entonces, la Ciudad y Junta de Morbería, considerando que se ha habilitado a la gente, que la cera y el cobre se hallan en el lazareto y que se ha cargado aceite en dicha embarcación, suplican la remisión de órdenes para ejecutar lo más conveniente en dicho caso. La respuesta, dada el 25 de marzo de 1724, consiste en ordenar a la Ciudad y Morbería que despidan al patrón y la embarcación con todo el género depositado en el lazareto, permitiéndole, en cambio, sacar el aceite embarcado. Todavía protesta el patrón sobre la dificultad de acondicionar todos los géneros del lazareto para poder volverlos a cargar, solicitando se le permita fletar otro barco, a lo que se le contesta el 30 de marzo de 1724 que cumpla lo ordenado ${ }^{44}$. Este caso brinda un claro ejemplo del modo en que funcionaban las instituciones insulares encargadas de prevenir el contagio en Mallorca.

El siguiente Auto de Morbería se refiere a la llegada a Palma el 24 de septiembre de 1730 de la tartana nombrada Nuestra Señora del Rosario, mandada por un patrón menorquín, con carga de trigo, siete tripulantes y

43 ARM., RA 666/9.

44 ARM., RA 666/9. 
seis pasajeros, uno de ellos un religioso, «los cuales fueron redimidos en Argel». El patrón manifestó que no había ningún enfermo a bordo, ni tampoco existía peligro de contagio en Argel y cercanías, corroborando la versión anterior dos marineros. Se recogieron los certificados del barco, figurando entre ellos un documento del religioso Francisco Navarro, de la Orden de la Santísima Trinidad, redentor de cautivos y Administrador de los Hospitales de Argel, y otro del cónsul inglés informando que en Argel se goza de buena salud. El Ayuntamiento acordó, contando con la aprobación del Teniente del Rey, por encontrarse ausente el Comandante General, admitir a la tripulación y pasajeros a cuarentena en el lazareto. El 2 de octubre de 1730 en presencia del morbero Guillermo Garcías fueron admitidos sin restricciones ${ }^{45}$.

\section{LA PESTE DE MESSINA}

Messina, situada en la costa oriental de Sicilia, padeció la peste durante el año 1743. Su ubicación estratégica, cerca de Nápoles, de Malta y las rutas de Levante, hizo que tal epidemia se viese con gran recelo, poniéndose en vigor nuevamente las consabidas medidas de prevención sanitaria. Se basaban sobre todo en la Instrucción del Real Acuerdo de 13 de noviembre de 1740, con ocasión de la peste de Argel. Tan sólo se cambiaron los nombres de los lugares infectados, y así donde antes se hablaba de Argel y Levante, ahora se hablará de Messina, Ceuta y lugares inmediatos (pues también se había localizado otra enfermedad infecciosa en Ceuta por aquellos años).

No debían ser admitidas las embarcaciones procedentes de Messina, mientras que las procedentes de Malta, Lípari e islas cercanas al Reino de Sicilia tenian que efectuar una cuarentena de 40 días. En cambio, las que viniesen del Reino de Nápoles, dadas las eficaces medidas de seguridad allí adoptadas, precediendo las diligencias de visita y fondeo y no existiendo sospecha de contagio, contarían sólo con una cuarentena prudencial. Cuando a mediados de agosto de 1743 se conoce la noticia de haber llegado la epidemia a las costas de Calabria, se precisó la obligación de vigiiar las costas de Mallorca con el mayor celo, "como se practicó en la ocasión del contagio de Marsella, escogiendo los Bayles y Regidores los hombres de mayor confianza, aunque sea aumentándoles el salario, para

45 ARM., AH $763 / 3$ 
que la falta de la debida satisfacción no pueda ser ocasión de emplearse en otros quehaceres" ${ }^{46}$.

Los años de 1743 y 1744 fueron difíciles en Mallorca, pues a las malas cosechas se añadió una misteriosa epidemia, iniciada en Palma a finales de 1744 y que luego se extendió por toda la isla. Se calcula que murieron unas 10.000 personas, durando hasta la primavera del año siguiente ${ }^{47}$. Por otro lado, la participación de España en la guerra de Sucesión de Austria contribuyó a agravar la situación.

Una serie de Autos de Morbería permiten acercarnos a la realidad de estos años en que se vigilaron especialmente las embarcaciones procedentes de Marsella y de Mahón. Así, el 27 de julio de 1743 llegó a Palma una tartana francesa, procedente de Marsella, con carga de 400 cueros y diversos géneros de ropa, además de un pasajero. Los Morberos acordaron «que en atención a que los cueros que vienen de Marsella, la mayor parte de ellos procede de Constantinopla y otras partes sospechosas de contagio..., han resuelto que se desembarquen en el Lazareto y se ventilen 20 días en atención a venir salados». En cuanto a las ropas al no tener la certeza de que fuesen originarias de Francia también se pusieron en cuarentena hasta nuevo aviso ${ }^{48}$.

Una tartana francesa, llegada desde Mahón el 29 de agosto, informó de que en esta última localidad se imponía una cuarentena de catorce días a las embarcaciones procedentes de Génova y Marsella, mientras se negaba la admisión a las de Sicilia y Nápoles. La tartana transportaba botas vacías y 82 barriles de atún salado y hubo de cumplir una cuarentena de catorce días ${ }^{49}$.

El 2 de septiembre arribó un jabeque mallorquín, procedente de Génova, sin más carga que algunas partidas de ropa para uso particular de algunos marineros. El patrón informó que dos navios de guerra ingleses habían intentado darle caza, pero había podido escapar. Se impuso a la embarcación una cuarentena de quince días con dos guardias de la salud dentro, cumplida la cual y no habiendo novedad podía ser admitida a práctica, si las autoridades aprobaban el dictamen de la Morberia ${ }^{50}$.

También a una embarcación francesa, llegada el mismo día en lastre y procedente de Mahón, se le impuso una cuarentena con dos guardias de

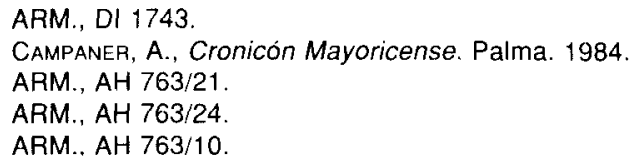


la salud dentro, siendo admitida el 15 de septiembre ${ }^{51}$. En cambio, una nave genovesa, llegada el 12 de septiembre desde Barcelona, cargada con piedras de molino, hubo de efectuar "cuatro días de purga a la vista del Capitán del Puerto sin guardias para excusar gastos", siendo admitida el 15 de septiembre tras el obligado reconocimiento médico ${ }^{52}$.

De la documentación examinada, toda correspondiente al año 1743, se deduce que las embarcaciones procedentes de Marsella suelen hacer 15 dias de cuarentena, 14 días las procedentes de Mahón y 4 dias las de Cataluña, mientras que para las llegadas de Génova el número de días es variable. En cuanto a los géneros textiles se les suele imponer una cuarentena de 20 días con la obligación de estar ventilados, pese a los certificados aportados que señalan que han salido de un puerto europeo, ya que se previene a los morberos contra los mismos por ser géneros susceptibles de introducir el contagio si se descuidan las precauciones de rigor. Las embarcaciones procedentes de Mahón suelen ir en lastre, habiendo descargado allí las mercancías embarcadas en una escala anterior, al contrario de las de Marsella, Génova o Cataluña, que transportan mercancías diversas.

Por lo que hace al año 1744 también existe constancia de la llegada a Palma de una serie de barcos mercantes: el 30 de marzo llega un navío holandés en lastre desde Marsella, al que se impone una cuarentena de 10 días ${ }^{53}$, otro navio holandés, arribado desde Marsella en lastre el 24 de abril para cargar aceite, recibe un trato similar ${ }^{54}$. En cambio, un barco genovés, procedente de Marsella con carga de trigo, anclado en Palma el 21 de agosto sólo deberá hacer ocho días de cuarentena. Todavía se reducirán más los plazos en ciertos casos: un barco genovés procedente de Mahón, con carga de trigo de Berbería, cera, indianas, manteca inglesa y cacao, todo sacado de los almacenes de aquel puerto, y 16 pasajeros, antiguos prisioneros de guerra en Menorca, que eran conducidos a Mallorca para ser entregados al Comandante General, deberá someterse a una cuarentena de seis días ${ }^{55}$.

\section{PREVENCIÓN Y CORSO}

Antes se ha hablado de la aplicación de medidas de prevención sanitaria en relación a los barcos mallorquines armados en corso. Según defi-

\footnotetext{
ARM., AH 763/49.

ARM., AH 763/8.

ARM., AH 763/17.

ARM., AH 763/30

ARM., AH 763/53
} 
nición clásica, el corso suponía "la empresa naval de un particular contra los enemigos de su Estado, realizada con el permiso y bajo la autoridad de la potencia beligerante» ${ }^{56}$, pero el corso también ha sido descrito acertadamente como un vehículo comercial propio de sociedades con una situación desventajosa en un orden comercial dado. Luego, «el corso es una forma de comercio", inseparable del comercio, del que participan los corsarios merced a sus actividades lucrativas ${ }^{57}$. De este modo, la actividad demostrada por mallorquines e ibicencos como corsarios, a lo largo de su historia, se explica en función de las características de sus respectivas sociedades y economías y, como mecanismo de participación en los flujos comerciales del Mediterráneo, ya desde la Edad Media, sin que el siglo XVIII constituya una excepción. Dadas las características del corso dicha actividad suponía un estado de guerra y el sometimiento a una jurisdicción que legalice sus presas, lo que lo distingue de la piratería. La posibilidad de que los corsarios introduzcan géneros sospechosos de contagio, o entren en contacto con navíos sospechosos, introduce un factor de riesgo sanitario a ojos de las autoridades. Así, la actividad del corso también deberá someterse al celo inspector de las autoridades sanitarias, las cuales le impondrán sus criterios teniendo en cuenta el peligro que pueda correr la salud pública.

En el caso que nos ocupa, no debemos olvidar que desde 1737 España y Gran Bretaña estaban en guerra, aparte del estado de hostilidad casi permanente que existía entre corsarios mallorquines y musulmanes, lo que brindaba la ocasión de depredar el tráfico comercial británico, sin despreciar otras presas, con vistas a obtener una rentabilidad adecuada.

El primer caso referenciado en nuestra documentación data de no. viembre de 1739 y, se incluye en un comunicado dirigido al Marqués de la Ensenada, dándole cuenta de la entrada en el puerto de Palma, el día 11, de los dos jabeques de los patrones Antonio Portell y Juan Santandreu con dos presas, una inglesa y otra francesa. Esta última fue apresada a once millas de Menorca, llevando "sesenta Moros como pasajeros y géneros de ropa, parte embarcados en Malta y parte en Túnez para conducir a Gibraltar». Estos pasajeros habían pasado al barco francés desde otras

56 Azcarraga, J. L., El corso marítimo. Madrid, 1950, p.27.

57 López NADAL, G. El corsarisme mallorqui a la Mediterrània occidental 1652-1698: un comerç forçat. Barcelona. 1986. Del mismo autor, "El corsarismo en las estructuras mercantiles: las fronteras del convecionalismo", en El comerç alternatiu: corsarisme $i$ contraban (Ss. XV-XVIII). Palma, 1990, pp. 267-276 y, “El corsarismo en el Mediterráneo entre los tratados de Utrecht y París (1715-1856): Primeras reflexiones", en Estudis d'História Econòmica, 1991.2, pp. 95-110. También, Martín Corrales, E., op. cit. 
dos naves inglesas venidas de Alejandría. Los corsarios, al no encontrar ninguna póliza de cargo entre la documentación entregada, la condujeron a Palma. La Junta de Morbería alarmada porque en Alejandría había habido peste y no constaba que el barco francés hubiese hecho cuarentena en parte alguna, resolvió, con el Ayuntamiento, el día 13, que en modo alguno se admitiese dicho barco, ni aun a rigurosa cuarentena, sino que se despidiese, medida que fue aprobada por el Comandante General. El cónsul francés se preocupó por lograr la libertad del barco apresado.

De modo que cuando el día 14 se informó a los armadores de los corsarios, para que usasen de sus derechos, convinieron en que el hecho de no llevar pólizas de cargo no era garantía suficiente para fundamentar sus pretensiones y desistieron de llevarlo a otro puerto, "por los perjuicios que ello les podría ocasionar". En vista de lo cual el barco quedó en libertad. Este caso ilustra el criterio de la Junta de Morbería, aunque al final la nave no fuese forzada a salir del puerto, sino que saliese por haber quedado libre, tras haber renunciado los armadores a defender sus derechos de presa ${ }^{58}$.

En Auto de Morberia, de 7 de noviembre de 1743, consta la llegada a Palma del jabeque mallorquín San Juan Bautista con un barco inglés apresado cerca de Porto Colom, con carga de abadejo, cuya tripulación había huido. Se decretó para la carga una cuarentena de veinte días en el lazareto y se pusieron dos guardias de la salud en el barco apresado ${ }^{59}$.

El jabeque mallorquín El Dulcísimo Nombre de Jesús entró con una presa inglesa en Palma el 19 de noviembre de 1743. La nave había sido apresada cerca de Cabrera, rindiéndose su tripulación, que informó que se dirigían a Génova desde Terranova con carga de bacalao. La tripulación y un pasajero que llevaban gozaban de buena salud, excepto el capitán una de cuyas piernas se accidentó en alta mar y un marinero con las piernas hinchadas. Se les impuso una cuarentena de veinte dias; el armador-corsario puso dos hombres en la nave apresada, el Almirantazgo otros dos y la Junta de Morbería dos más como guardias de la salud. Un cirujano se encerró en el lazareto con los tripulantes para cuidar al capitán, además de un guardia de la salud, y se convino que los ingieses recibiesen "alimentos de enfermo", lo que le fue comunicado al armador, "apercibiéndole que si no lo ejecutaba, lo ejecutaria a sus costas la Morberia, como también que hiciese llevar al lazareto seis o siete jergones de paja y man-

58 Archivo General de Simancas (= AGS): Secretaria de Marina. Corso. Legajo 525.

59 ARM., AH 763/26. 
tas". El 3 de diciembre se practicó un reconocimiento médico en el lazareto, en presencia de los morberos, y se consideró que las dolencias del capitán inglés y del marinero no presentaban peligro de contagio, por lo que se les franqueó la entrada el día 7. El Comandante General ordenó que los ingleses fuesen al Cuartel de Dragones, los enfermos al hospital y el pasajero quedó libre ${ }^{60}$.

El último caso localizado data de 24 de noviembre de 1743. Se apresó un navío holandés cerca de Formentera, procedente de Argel, con dos pasajeros turcos y carga de trigo por cuenta de ellos. Interrogado el capitán sobre la situación sanitaria en Argel, se remitió al certificado expedido por el cónsul francés en aquel lugar, de fecha 26 de octubre, donde se declaraba que desde hacía dos meses nadie había muerto de peste. Los morberos convinieron que el jabeque corsario y su tripulación no debian salir del puerto de Palma sin hacer antes una rigurosa cuarentena de cuarenta días, llevando la ropa de los marineros y todo lo demás al lazareto para su ventilación ${ }^{61}$.

Así como las dos presas inglesas con carga de bacalao no presentaban complejidad a la hora de aplicar las normas de prevención sanitaria, se advierte la incomodidad y recelo de los morberos ante cualquier trato con pasajeros y géneros procedentes del Norte de Africa por el riesgo de contagio, incluyendo a los mismos corsarios en las cuarentenas.

\section{LA PESTE DE ARGEL DE 1752}

A la hora de hablar de esta epidemia que tampoco será la última en el ámbito mediterráneo, no debemos olvidar las disposiciones sanitarias aplicadas en ocasiones anteriores que constituirán el marco normativo vigente en Mallorca. En aplicación de las mismas surgirán consultas y conflictos entre las mismas autoridades de los municipios mallorquines, dirigidas a la Audiencia de Palma, que, mediante Real Acuerdo, deberá resolver las reclamaciones planteadas, al tiempo que vigilará el estricto cumplimiento de lo ordenado, interviniendo de oficio cuando lo crea necesario.

El 10 de junio de 1752 el gobernador de Ibiza remitió una carta a las autoridades de Mallorca, informando de la aparición de la peste en Argel. Dicha noticia provenía del patrón de un barco genovés escapado de Argel

60 ARM., AH 763/20.
61 ARM., AH 763/29. 
el día 6 de junio al conocer las primeras defunciones. También huyeron otras tres embarcaciones "mahonesas» cargadas de trigo, mientras quedaban en Argel un navio y dos polacras francesas cargando lana. La alarma que despertó esta noticia en las autoridades de lbiza y el temor de que la nave genovesa estuviese infectada, les indujo a despedirla sin admitirla a cuarentena. Sólo le proporcionaron algunos víveres, dejados en un escollo, sin querer aceptar dinero a cambio, y poniendo una barca de guardia para evitar toda comunicación con la isla. Inmediatamente el gobernador de lbiza despachó varias embarcaciones para comunicar la noticia al gobernador de Alicante, encargándole de que diese aviso a Cartagena y al Marqués de la Ensenada, e informó asimismo a la isla de Mallorca.

Conocida la noticia en Mallorca, el Real Acuerdo remitió cartas a las autoridades municipales, fechadas el 14 de junio, ordenando la ejecución de las providencias habituales, y las medidas de vigilancia necesarias, especialmente las contenidas en la Ordenanza de 27 de noviembre de $1720^{62}$.

El Ayuntamiento de Palma en fecha 12 de junio habia comunicado la noticia de la peste de Argel a los jurados de Mahón, que respondieron en carta recibida en Palma el 16 de junio agradeciendo el aviso y señalando haber tomado las precauciones de rigor. También se envió otra carta desde Mahón, dirigida al Magistrado de la Sanidad en Palma, donde se informaba de que, habiendo llegado a Mahón varias embarcaciones procedentes de Argel, con la noticia de la peste, no fueron admitidas a práctica, sino despedidas del puerto, donde tampoco se dejó entrar a las embarcaciones procedentes de Berbería. Se confirmó, pues, desde Menorca la noticia de la peste y se explicaron las medidas de precaución sanitaria adoptadas, de modo que, según el parecer de los jurados de Mahón, "esperamos ser aliviados de la cuarentena, que según estamos informados, manda V.S. ${ }^{a}$ hacer a nuestros Bastimentos, pues no parece existir motivo para ello" 63. Confirmada la noticia, el Real Acuerdo remitió otra carta a los municipios el 21 de junio, ordenando que, "sin perder un instante y a cuenta del común de cada Villa", se hicieran las rondas necesarias y se aplicasen las normas de prevención sanitaria de años anteriores.

Como se recordará, los guardias de vigilancia en cada puesto debían recibir el armamento y munición correspondiente que, normalmente, les

63 ARM., Audiencia XLVII/3. 
era suministrado sin problemas. Pero no siempre sucedia de esta manera y, así, el 24 de junio, el bayle de Alcudia protestó porque el gobernador de aquella plaza no había querido proporcionar las armas necesarias a los guardias, sacándolas del Almacén Real, contra recibo, según era costumbre. El gobernador alegaba no haber recibido tales órdenes del Comandante General. El 1 de julio el Real Acuerdo comunicó al bayle de Alcudia que el Comandante General había cursado las órdenes oportunas dirigidas al citado gobernador ${ }^{64}$.

El 18 de julio el Real Acuerdo escribió al bayle de Sóller, inquiriendo si se había permitido desembarcar allí un pliego remitido desde Barcelona, contraviniendo las normas de prevención del contagio. Se justificó tal proceder al tratarse de pliegos del rey, según señaló el patrón que los trajo, los cuales, además, fueron examinados por el gobernador desde la orilla antes de permitir su desembarco ${ }^{65}$.

El 22 de julio el bayle de Manacor había enviado al Regente de la Audiencia de Palma una carta en la que le informaba como desde la barca de la Renta del Tabaco, que contorneaba la isla, se descubrió la ausencia de los vigilantes que debían cubrir la torre de Cala Manacor. Por tal ausencia injustificada los dos torreros fueron encarcelados en Manacor, siendo nombradas dos personas para cubrir su puesto. El Real Acuerdo, en fecha 24 de julio, decidió que siguiesen en prisión, "a la disposición del Comandante General, por haber faltado a su deber de vigilancia». Este señaló que si el Regente de la Audiencia no había prescrito el castigo, el bayle hiciese lo que le pareciese regular, "para que en adelante estén más vigilantes y cuidadosos". La decisión del bayle fue ponerlos en libertad, una vez dada caución y fianza ${ }^{66}$.

El 11 de agosto el bayle de Artà comunicó al de Manacor cómo, habiéndose presentado un barco francés en la playa del Port Vell, había intentado desembarcar, diciendo que venía de Valencia, y al serle prohibido y persistir en su actitud, los guardias de la salud habían hecho algunos disparos, de modo que se había puesto a la vela, yendo hacia Levante, por lo que debía estar prevenido y en guardia. El mismo día el bayle de Manacor transmitió por escrito la anterior información al de Felanitx ${ }^{67}$.

Hasta el 22 de mayo de 1754, mediante Decreto del Capitán General de Mallorca, a petición de los Síndicos Forenses, no se quitarán las guar-

\footnotetext{
ARM., Audiencia XLVII/31.

ARM., Audiencia XLVII/30.

ARM., Audiencia XLVII/37.

ARM., Audiencia XLVII/21.
} 
dias extraordinarias de las villas marítimas, «teniendo en cuenta que ya se habían quitado las de Palma, había cesado el contagio de Argel y era necesaria la gente para recoger las mieses", novedad que se comunicó a las autoridades municipales afectadas dos dias después ${ }^{68}$.

Los Autos de Morbería de este periodo, no muy numerosos, no ofrecen grandes novedades: los barcos, procedentes de Menorca, con independencia de que vayan cargados o en lastre, suelen realizar una cuarentena de diez dias, mientras que los procedentes de otros puertos españoles 0 de Marsella suelen hacerla de seis días.

Se puede destacar la reiteración de la prohibición de admitir embarcaciones que procedan de lugares donde se padece la peste, y así las autoridades de Mallorca prohibieron el acceso a dos tartanas francesas procedentes de Argel, en las que viajaban junto con religiosos de la Orden de la Merced 239 antiguos esclavos redimidos; y aunque desde las embarcaciones se comunicó que todos estaban sanos, conociéndose que todavía persistía la peste en Argel, se les prohibió desembarcar ${ }^{69}$.

Al hablar de la peste de Marsella de 1720 se comentaron las dificultades financieras del Ayuntamiento de Palma. Con la peste de Argel de 1752 tal problema reaparece. Así, el 1 de agosto de 1752 el Regente y oidores de la Audiencia de Palma, "estando en General Acuerdo", comunican al Ayuntamiento de la ciudad que presente memoria de las medidas necesarias para la prevención de la peste de Argel, y señale las obligaciones que suple la Universal Consignación. El Ayuntamiento contestó mediante memorial elevado a la Audiencia, donde hizo constar que los individuos de cada una de las seis parroquias de Palma, con edades comprendidas entre los 16 y los 65 años, sumaban 5.212, "exceptuándose los Caballeros y los Ciudadanos que hacen el servicio de las rondas, y los notados en la Parroquia de Santa Cruz por ausentes del Reino". Por otro lado, se empleaban 28 individuos en las guardias maritimas del distrito de Palma y 14 individuos en los tres barcos para guarda de la salud, más otros dos individuos, uno para guiar las rondas de Levante y otro para avisar al caballero regidor de servicio en el muelle de la llegada de las embarcaciones. O sea, 44 individuos empleados en tareas de prevención sanitaria.

Al hablar de los puestos de vigilancia, el Ayuntamiento expuso, a la luz de la experiencia de 1720, que las personas llamadas no estaban dispuestas a cubrir los puestos de guardia y preferían pagar una contribu-

68 ARM., Audiencia XLVII/14.

6. ARM., Audiencia VIII/208. 
ción, yendo en su lugar personas escogidas a propósito y de confianza con un salario diario. A cada uno de los guardias se le pagaban 6 sueldos (moneda mallorquina) diarios, lo que daba un total de gastos mensuales de 252 libras. Al tener que pagar a las personas de confianza empleadas en las guardias, el Ayuntamiento consideraba que dichos gastos constituirían "carga personal de los habitantes de Palma", a satisfacer a la Tabla de Depósitos. De acuerdo con la idea anterior de la contribución se calculaba un importe de 67 días (los últimos de junio, más julio y agosto ya vencidos), lo que equivalía a 562 libras y 16 sueldos, más 56 libras y 5 sueldos para los exactores, lo que ofrece unos gastos iniciales de $619 \mathrm{li}$ bras, 1 sueldo y 7 dineros. Los gastos anteriores, repartidos entre los 5.212 contribuyentes, implicaban que cada uno debiese pagar 14 dobleros, y atendiendo a los que pudiesen eximirse, "por edad, enfermedades, o hallarse empleados en empleos públicos y personales", un total de 16 dobleros.

El fiscal del rey señaló, ante el memorial, que las medidas de prevención contra el contagio de la peste constituían uno de los casos en que «se pueda valer del dinero de la Consignación, o tomándole a censo sobre ella, y deben contribuir por medio de la Talla los eclesiásticos, los caballeros del Hábito de cualquier Religión Militar, aunque sea de San Juan, y otros que gozan de Franqueza, y demás exentos como son los Ministros y Oficiales del Tribunal del Santo Oficio de la Inquisición». Es decir, se proponía implicar a todos los estamentos en la obligación de contribuir a los gastos.

Se aducía en tal sentido que, estando todos interesados en la conservación de la salud, no era justo que se obligase a pagar 1 sueldo y 4 dineros mensuales sólo a los contribuyentes comprendidos entre los 16 y los 65 años de edad. En lugar de la contribución se consideraba más idónea la talla general. El fiscal concluía que muchos pobres y otros que no lo eran sin duda preferirian hacer las guardias antes que pagar la capitación al Ayuntamiento.

El 9 de agosto se dio traslado del escrito del fiscal a la Ciudad y a la Universal Consignación para que alegasen lo que tuviesen por conveniente. El Ayuntamiento contestó el 29 de agosto, oponiéndose a las pretensiones del fiscal por diversos motivos. Se señaló que las guardias costeras de toda Mallorca se hacen por capitación, como en 1720, y la Parte Forense (resto de la isla) ya contribuye de esta manera. Si en la talla el criterio territorial de pago incumbe a todo el Reino, mal puede exigirse a la Parte Forense que pague dos veces. Además, el criterio de ver en la talla un remedio más equitativo se desmiente al constatar que sólo están obli- 
gados a pagar los individuos que poseen bienes raíces o de negocio. Y si los caballeros no pagaban capitación era porque realizaban el servicio de rondas, de modo que si pagasen la talla se les deberían excusar las rondas. En cuanto a que muchos escogiesen las guardias, con su cortejo de incomodidades, antes que pagar la capitación se consideraba discutible. Por último, se alega «que a los Jurados y Morberos toca la custodia de la Peste, y enfermedad de contagio, y todo lo que mira a lo político que fuera conveniente para ello".

En su respuesta la Universal Consignación expuso que no se habia opuesto, ni se oponía a que se tomasen los efectos más expedidos de la Consignación para la prevención de la peste de Argel, "con tal que se reemplace por talla general todo lo que se gastare de la Consignación». A tal efecto, se había acordado una talla general de 4.000 pesos, "mientras en 4 del corriente ya se acordó con la Ciudad el tomarse para dicho fin el que se tomase el dinero de la Consignación con reintegración de su importe".

Finalmente, por auto de la Audiencia, de 5 de octubre de 1752, se aprobó la talla general como medio de contribuir a los gastos de las guardias marítimas y todos los demás originados por la precaución del contagio de Argel ${ }^{70}$.

\section{CONCLUSIONES}

A lo largo de este trabajo se ha intentado comprender cómo se aplicaron las medidas de prevención sanitaria en el marco del tráfico marítimo, tomando a Mallorca como espacio de referencia y el periodo comprendido entre 1718 y 1756 como marco cronológico. Ante todo se ha tratado de averiguar en que consistían estas medidas y, para ello se ha utilizado como fuente primordial la documentación correspondiente. El análisis de la legislación aplicable se ha completado con el estudio de las instituciones en presencia y las visitas documentadas a las embarcaciones arribadas al puerto de Palma (Autos de Morbería).

La documentación localizada no constituye sino una muestra dispersa y variada de lo que supuso la puesta en práctica de la prevención sanitaria en el periodo estudiado. En relación a la Junta de Morbería se echa de menos la existencia de un fondo documental homogéneo, en comparación

7o ARM., Audiencia VIII/208. 
con otras instituciones. Igualmente, el tema de la financiación de las medidas de prevención sanitaria se ha revelado como crucial, y si bien se dispone de documentos también queda mucho por dilucidar, pues aunque se conoce el cobro de gastos de cuarentena no ha aparecido relación de los mismos.

La peste de Marsella es la epidemia con la que la nueva dinastía inaugura, en cierto modo, su política de prevención sanitaria, pero ésta pese a presentar innovaciones no supone un corte brutal con el periodo anterior, no, al menos, en el caso de Mallorca, donde subsistirá la Junta de Morberos hasta 1756, experimentando, eso sí, los cambios que propicia el nuevo marco institucional. Su actuación no será independiente del Ayuntamiento de Palma, la Audiencia y el Capitán General, dependiendo de estos dos últimos la tarea de ordenar y supervisar la aplicación de las medidas de prevención en todo el ámbito insular.

Las disposiciones normativas aplicadas con ocasión de la peste de Marsella constituirán el fundamento de las actuaciones posteriores, con ocasión de otras alarmas hasta llegar a la peste de Argel de 1752. El desempeño de tareas de vigilancia costera para prevenir la llegada de cualquier embarcación sospechosa se basará en la Instrucción de 27 de noviembre de 1720 , aplicada también en 1752. Es a través de algunos documentos oficiales, presentados por el Ayuntamiento de Palma, como se constata el descontento que las medidas de prevención sanitaria podían suscitar entre los mallorquines, dado el gravamen personal y financiero que conllevaban.

Estas medidas de prevención sanitaria, sobre todo en los momentos más graves, restringieron sin duda el tráfico comercial, pero nunca lo suprimieron del todo, ni tampoco podía ser esa su intención, ya que entraba en juego la supervivencia misma de los habitantes de Mallorca y los diversos intereses mercantiles presentes. En efecto, siendo deficitarias las cosechas durante muchos años del periodo estudiado, se imponía el recurso a las importaciones de trigo, incluso pese al posible riesgo de contagio. Y las importaciones de los productos necesarios para la isla iban parejas con las exportaciones de los productos de ésta, especialmente el aceite enviado a Marsella.

A favor de las medidas adoptadas puede decirse que durante el siglo XVIII Mallorca no padeció ninguna epidemia introducida desde el exterior, lo que no había sucedido en siglos anteriores, ni sucederá tampoco durante el siglo XIX.

Pese al conocimiento alcanzado todavía quedan muchos temas pendientes de investigación, como la evolución de la prevención del contagio 
en Mallorca a partir de 1756, la posibilidad de estudiar el lazareto de Palma y las cuarentenas allí realizadas, por no citar sino unas cuantas cuestiones, estableciendo estudios comparativos con las medidas para evitar el contagio tal y como se aplicaron en otros lugares. Se trata, pues, de una línea de investigación que permanece abierta y cuyas conclusiones sólo podrán consolidarse y ampliarse con nuevas búsquedas, nuevos hallazgos documentales y un intercambio fructífero con otros investigadores. 